\title{
A Test Device for Premixed Gas Turbine Combustion Oscillations
}

\section{Technical Note}

George A. Richards

Randall S. Gemmen

M. Joseph Yip

March 1996

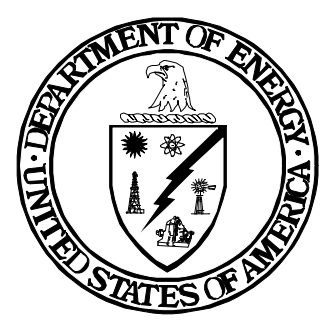

U.S. Department of Energy

Office of Fossil Energy

Morgantown Energy Technology Center

P.O. Box 880

Morgantown, WV 26507-0880

(304) 285-4764

FAX (304) 285-4403/4469

http://www.metc.doe.gov/ 


\section{Disclaimer}

This report was prepared as an account of work sponsored by an agency of the United States Government. Neither the United States Government nor any agency thereof, nor any of their employees, makes any warranty, express or implied, or assumes any legal liability or responsibility for the accuracy, completeness, or usefulness of any information, apparatus, product, or process disclosed, or represents that its use would not infringe privately owned rights. Reference herein to any specific commercial product, process, or service by trade name, trademark, manufacturer, or otherwise does not necessarily constitute or imply its endorsement, recommendation, or favoring by the United States Government or any agency thereof. The views and opinions of authors expressed herein do not necessarily state or reflect those of the United States Government or any agency thereof. 


\section{Contents}

$\underline{\text { Page }}$

$1 \quad$ Introduction $\ldots \ldots \ldots \ldots \ldots \ldots \ldots \ldots \ldots \ldots \ldots \ldots \ldots \ldots$

2 Background and Design Requirements $\ldots \ldots \ldots \ldots \ldots$

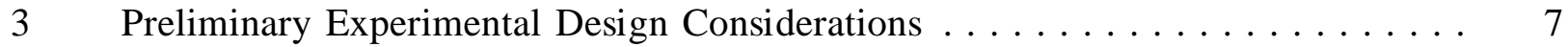

4 Experiment Description $\ldots \ldots \ldots \ldots \ldots \ldots \ldots$

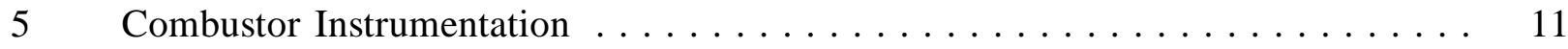

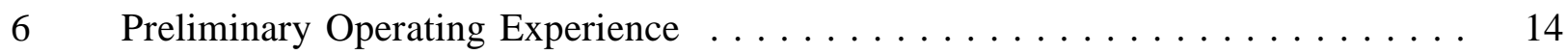

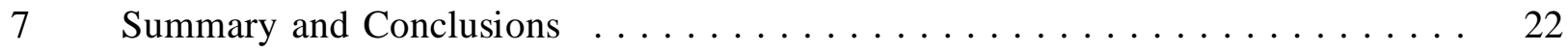

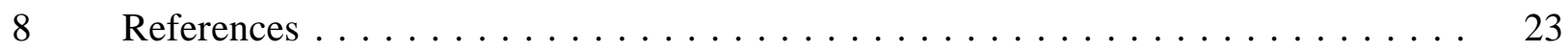

\section{List of Figures}

$\underline{\text { Figure }}$

$\underline{\text { Page }}$

1 A Schematic of the Processes Occurring During Combustion Oscillations _... 6

2 Comparison of Acoustic Geometries Considered for Combustor Design . . . . . . 7

3 Cut-Away and Cross-Section Views of the Test Combustor . . . . . . . . . . 12

4 Fiber Optic Probe for Viewing $\mathrm{OH}$ Chemiluminescence . . . . . . . . . . . 13

5 Pressure and $\mathrm{OH}$ Signals for Case P1 Listed in Table $1 \ldots \ldots \ldots \ldots$

6 Pressure and $\mathrm{OH}$ Signals for Case P2 Listed in Table $1 \ldots \ldots \ldots \ldots$

7 Pressure and $\mathrm{OH}$ Signals for Case P3 Listed in Table $1 \ldots \ldots \ldots \ldots$

8 Pressure and $\mathrm{OH}$ Signals for Case P4 Listed in Table $1 \ldots \ldots \ldots \ldots$

9 Effect of Reference Velocity on the RMS Pressure at Different

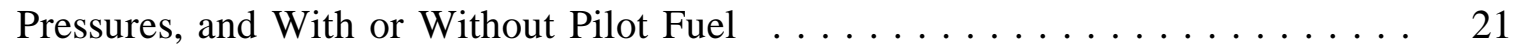

\section{List of Tables}

Table $\quad \underline{\text { Page }}$

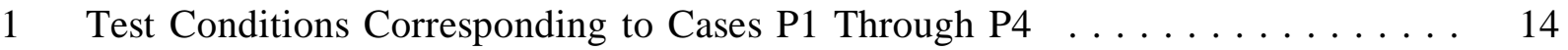




\section{Introduction}

This report discusses the design and operation of a test combustor suitable for studying combustion oscillations from commercial-scale gas turbine fuel nozzles. To meet stringent $\mathrm{NO}_{\mathrm{x}}$ emission goals, most stationary gas turbine vendors have adopted some form of lean, premixed (LPM) combustion (Lefebvre 1995; Beer 1995). The low flame temperatures associated with lean combustion produce low $\mathrm{NO}_{\mathrm{x}}$ levels, but LPM combustion is often accompanied by undesirable pressure oscillations. Because of the resulting vibration, even small amplitude pressure oscillations can damage engine hardware, and must therefore be eliminated during the development of new fuel nozzles and combustors. Unfortunately, the oscillations themselves are linked to the acoustic modes and acoustic gain (or loss) of a specific combustor geometry. Thus, tests of a single fuel nozzle in a conventional test stand usually do not reproduce the oscillating behavior that is found during complete engine testing. This increases the cost and time of new engine development because remedial modifications must be performed on the multi-nozzle, full-scale combustor.

As part of the U.S. Department of Energy's Advanced Turbine Systems Program (Alsup, Zeh, and Blazewicz 1995), the Morgantown Energy Technology Center (METC) has developed a single-nozzle combustor that can be used to study the oscillating behavior of individual gas turbine fuel nozzles. This test combustor differs from conventional singlenozzle test rigs because it is designed to produce an acoustic environment suitable for studying combustion instabilities. As described by Halow et al. (1994), the METC facilities are available for collaborative research and development with industrial, university, and government partners under a variety of cooperative arrangements. The emphasis of the present work is natural gas combustion for stationary gas turbines, although the techniques described here may be useful to investigate liquid fuel nozzles as well. In this report, we describe the combustor design, capabilities, and relevant instrumentation. Initial operating experience is also presented, along with preliminary data suggesting the important role of the nozzle reference velocity and air temperature on combustion oscillations. 


\section{Background and Design Requirements}

Dynamic pressure oscillations occur when heat release variations couple with the acoustic modes of a given combustor geometry. The variation in heat release can come from many different mechanisms, including vortex shedding, mixing variations, acoustic feedback to the fuel or air system, and other processes. Putnam (1971) describes many of the relevant processes in industrial burners. Yang and Anderson (1995) and Harrje and Reardon (1972) describe oscillating processes occurring in liquid fuel rockets. Review articles by Candel (1992) and McManus et al. (1993) describe the oscillating mechanism in a variety of burner applications. Whatever the specific mechanism, the basic features of all oscillations are the same: pressure waves in the combustor must couple with the heat release variation via a feedback mechanism. The situation is shown schematically in Figure 1 as a closed loop system. A variation in the heat release rate, $\dot{Q}(\mathrm{t})$, produces a momentary disturbance in the acoustic field inside the combustor. The combination of acoustic reflections in the combustor and acoustic losses determine the resulting pressure disturbance, $\mathrm{P}(\mathrm{t})$. If this pressure provides properly timed feedback to the combustion process (i.e., a change in fuel flow rate or mixing), an oscillation can occur. The mathematical statement of the requirement for oscillations is the well-known Rayleigh criterion:

$$
1 / \mathrm{T} \int_{0}^{\mathrm{T}} \int_{\mathrm{v}} \mathrm{P}(\overrightarrow{\mathrm{x}}, \mathrm{t}) \dot{\mathrm{Q}}(\overrightarrow{\mathrm{x}}, \mathrm{t}) \mathrm{dV} \mathrm{dt}>\text { acoustic losses }
$$

The term on the left is the product of heat release and pressure fluctuations integrated throughout the combustor volume, and averaged over a time $\mathrm{T}$, which is the oscillation period. This integral must exceed the acoustic losses for oscillations to grow. A limit cycle oscillation will exist when the losses balance the driving by the heat release fluctuation. Thus, to mimic gas turbine combustion oscillations in a test device (as opposed to a full engine), one should use a test environment having comparable acoustic gain or losses. Likewise, the feedback between the pressure and heat release fluctuation must be the same between engine and test device.

For many instability mechanisms, the feedback between pressure and heat release is determined by the fuel nozzle and the flame geometry. We use the term flame geometry to describe the location and shape of the flame front relative to the fuel nozzle. The flame geometry is important because the timing of the feedback will be different if the flame is lifted off the nozzle, versus closely attached. Thus, where possible, in the design of singlenozzle tests, the flame geometry should be that which exists in the final engine. By testing the actual fuel nozzle hardware, most of the nozzle feedback can be replicated in a singlenozzle test. However, a careful evaluation of the acoustic boundary conditions on both the fuel and air supplies should be performed. It may be necessary to duplicate some aspects of these boundary conditions to ensure that the fuel and air response is representative of the final hardware. Even with these precautions, it is not certain that the test device will mimic every aspect of the feedback that will occur on an engine. For example, when nozzle to nozzle interactions occur on an engine, a single-nozzle test will obviously not duplicate the feedback. 


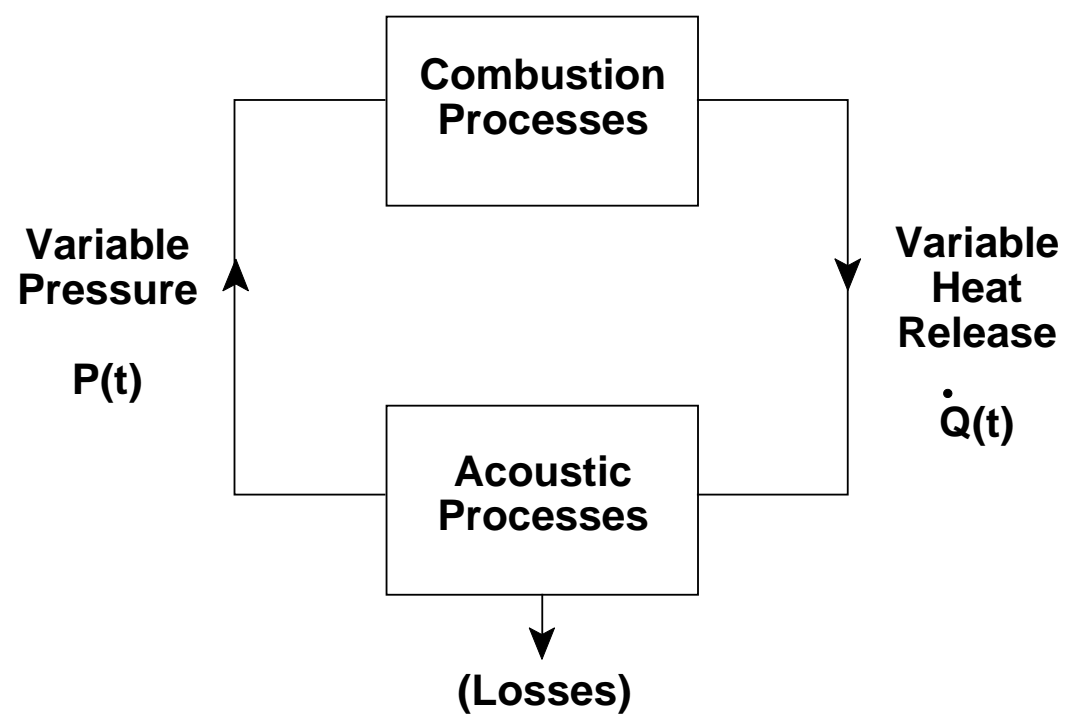

Figure 1. A Schematic of the Processes Occurring During Combustion Oscillations. Feedback between the acoustic pressure $\mathrm{P}(\mathrm{t})$ and combustion heat release variation $\dot{Q}(\mathrm{t})$ sustains oscillations.

In spite of this limitation, there is still an incentive to eliminate instability mechanisms associated with single nozzles before tackling the problem of multiple nozzles.

While some aspects of the feedback can be simulated in a test stand, the acoustic gain or loss occurring on the engine cannot be easily copied on a test device. The acoustic properties of the engine combustor are affected by the presence of the downstream hardware, such as the turbine nozzle. This is the reason why combustor tests performed in isolation do not typically replicate the oscillating behavior that may (or may not) exist during final testing of the assembled engine. Single-nozzle development is often conducted in a can or tubular combustor, having a very large exhaust opening terminated by spray quench water. The large exhaust opening provides an easy exit passage for acoustic waves, and the water quench produces significant acoustic damping. These features make it difficult to observe oscillations in traditional can-type test rigs.

As an alternative to replicating the acoustic environment of a full combustor, it is possible to build a test device having very low acoustic losses at frequencies that have been observed on the full engine design. This allows subsequent development to occur on just a single nozzle. With some exceptions (discussed later), a nozzle that is stable in a test combustor having very low losses should also be stable in the final engine application where greater acoustic losses are present. This report describes a test combustor with low acoustic losses and a natural frequency that can be changed with minor modifications. To date, the combustor has shown comparable oscillations between single-nozzle results and oscillations observed in a full engine test. 


\section{Preliminary Experimental Design Considerations}

To keep the design simple, we considered just two possible acoustic geometries (Figure 2). To produce a similar flame geometry as existed in the engine application, our first design requirement was that the combustion chamber diameter approximately match the diameter found in the engine combustor (or annular height); in this case, that was $19.8 \mathrm{~cm}$ (7.8 in). Starting with Figure 2, the so-called 1/4 wave geometry will produce resonant frequencies inversely proportional to the length $\mathrm{L}$. This assumes that the combustor exit does not acoustically interact with the pressure vessel and spray quench system further downstream. Because the pressure vessel inner diameter was only slightly larger than the combustion chamber $(25.6 \mathrm{~cm}$ [10.1 in]), it was likely that some coupling would exist between the $1 / 4$ wave tube and the pressure vessel plenum.

To avoid this complication, we considered a Helmholtz geometry (Figure 2). In this geometry, the acoustic pressure in the combustion chamber drives the slug of gas in the resonator neck, so that the natural frequency is established by the mass of gas oscillating in the neck and the "compliance" of the gas in the combustion chamber. At the exhaust of the neck, the area expansion (larger than Figure 2) reduces the acoustic interaction with the downstream pressure vessel and the spray quench. A further advantage of the Helmholtz design is that the neck region of the combustor can be modified or relocated to excite different natural frequencies. The $1 / 4$ wave geometry would require changes to the length of the quarter wave tube, meaning that the spray quench in the downstream exhaust duct (not shown) would need to be moved.
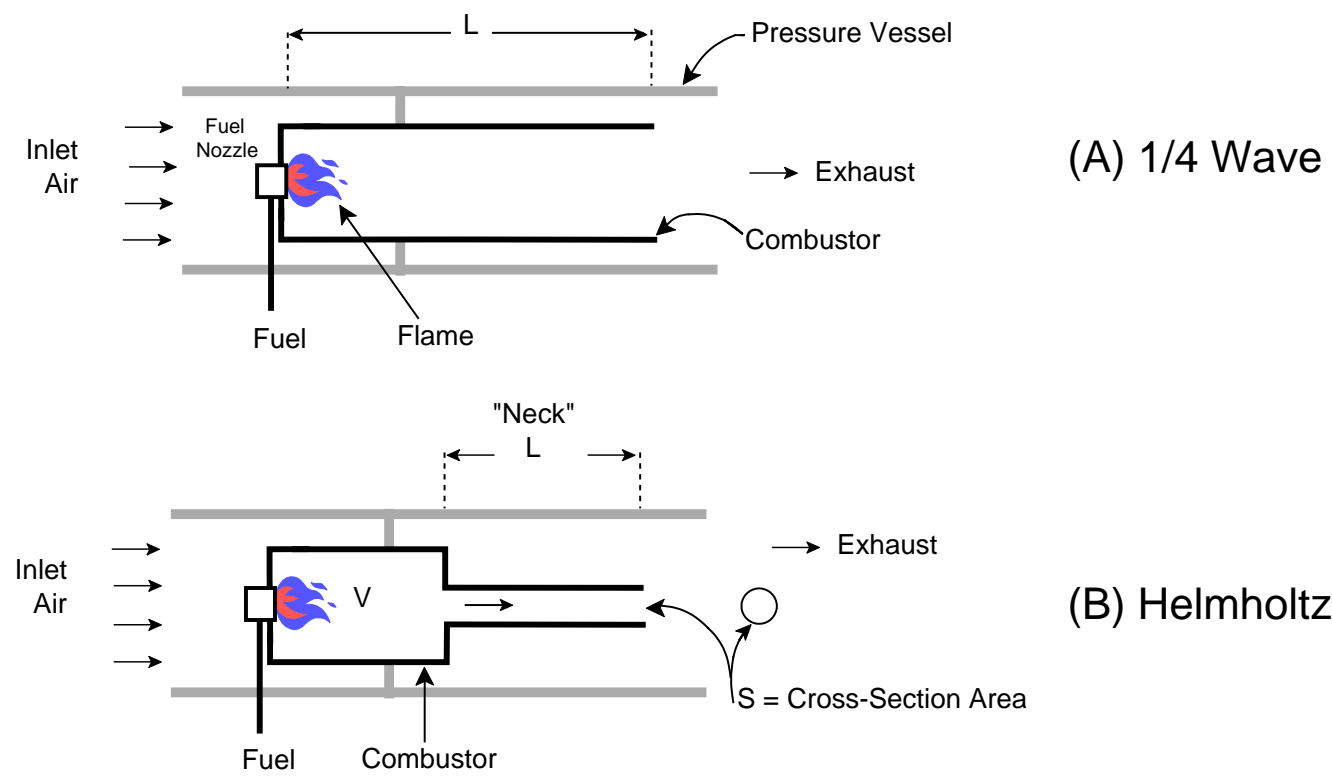

(B) Helmholtz

Figure 2. Comparison of Acoustic Geometries Considered for Combustor Design. The 1/4 wave resonator (a) is a tube of length L. The Helmholtz geometry (b) is defined by the combustion volume $\mathrm{V}$, and an exit neck with cross section area $\mathrm{S}$, and length $\mathrm{L}$. 


\section{Experiment Description}

Having established that a Helmholtz resonator provides an improved acoustic design, we now describe the combustor in detail. Figure 3 shows a cut-away and cross-section view of the combustor and pressure vessel. Air is supplied to the combustor from an inlet plenum. METC's combustion facilities can supply up to $1.4 \mathrm{~kg} / \mathrm{s}(3 \mathrm{lbm} / \mathrm{s})$ of unvitiated air at inlet temperatures up to $840 \mathrm{~K}\left(1,050{ }^{\circ} \mathrm{F}\right)$ and pressures up to 30 atmospheres. The experiment described here is limited to pressures up to 11 atmospheres by certain components in the pressure vessel design. The facilities include gas sampling capabilities for major species such as $\mathrm{NO}_{\mathrm{x}}, \mathrm{CO}$, and UHC. For a complete description of the facility capabilities, see Halow et al. (1994).

Early operating experience with this combustor showed that the combustor air supply should be diffused where it enters the inlet plenum. Our initial design supplied air to the inlet plenum via two $2.54-\mathrm{cm}$ (1.0-in) lines, with no precaution to diffuse the entering jets. This led to irregular combustion behavior at lean operating conditions because vortex shedding from the jet entry would cause fluctuations at the fuel nozzle. This problem was solved by re-directing the entry jets against the wall of the inlet plenum, thus diffusing the flow.

The fuel nozzle is mounted between the inlet plenum and the combustion zone. Fuel and air mix in the nozzle, and the flame is attached downstream of the nozzle. The nozzle used here was a commercial prototype that produced oscillations during full engine combustor testing, but not during conventional single-nozzle tests. The nozzle was typical of current gas turbine nozzle design, using swirl stabilization and a central pilot flame. The control valves on this experiment allow natural gas fuel flow rates up to $0.0263 \mathrm{~kg} / \mathrm{s}(208 \mathrm{lbm} / \mathrm{h})$, with a separately controlled pilot fuel flow rate of up to $0.0053 \mathrm{~kg} / \mathrm{s}(41.6 \mathrm{lbm} / \mathrm{h})$.

The combustor walls are formed by a water-cooled liner fabricated from $20.3 \mathrm{~cm}$ (8 in) Schedule 80 pipe (304 stainless steel). The pipe is fitted with a rolled sheetmetal jacket, forming a passage for water cooling. Likewise, the front of the combustor is formed from two metal plates, with water cooling circulating between the plates. A central hole in the water-cooled plates will accept nozzles with an external diameter up to $8.9 \mathrm{~cm}$ (3.5 in). The interior of the combustion chamber (i.e., the Schedule 80 pipe) was machined to an inside diameter of $19.8 \mathrm{~cm}$ (7.8 in) with an eccentricity of less than $0.038 \mathrm{~cm}(0.015 \mathrm{in})$. Precise tolerances were needed to allow the refractory plug and seal (described below) to be easily relocated.

The use of water-cooled combustor walls represents a compromise. The cold combustor walls will obviously lead to higher $\mathrm{CO}$ emissions than would occur in an engine application. However, the alternative of building a conventional air-cooled liner presents an acoustic problem: one cannot easily determine the acoustic losses occurring at the liner walls. Because we wanted to produce a combustor having very low acoustic losses, we decided to use acoustically hard, water-cooled walls. This will have two effects on the data. First, as noted already, we can expect the $\mathrm{CO}$ emissions to be higher than in the engine. Because our goal was to study the instabilities, we decided to accept this compromise. Second, we can 
expect the root mean square (RMS) pressures to be higher than in an engine, because the acoustic losses are low compared to the engine combustor. As explained previously, this was a desirable effect, since lower acoustic losses would permit verification testing of stable nozzle designs.

To achieve oscillations, it is necessary to excite some acoustic mode associated with the Helmholtz combustor geometry. The Helmholtz geometry is determined by the cylindrical combustion zone and the resonator neck (Figure 3). The neck of the resonator is an annular refractory plug mounted on a water-cooled ring (like a donut), attached to the back of the plug. The water-cooled ring carries a graphite packing seal that is compressed by a metal ring. The metal ring is forced out against the combustor walls by set screws, thereby locking the entire plug at one axial position. The resonator neck dimensions ( $\mathrm{S}$ and L, Figure 2) can be easily modified by simply re-casting a different plug. Likewise, the resonator volume (V, Figure 2) can be changed by relocating the plug along the axis of the combustor. These dimensions are established by the desired resonant frequencies (explained later).

Spray quench water is atomized downstream of the refractory plug and sealing ring by a pair of air assist atomizers. These atomizers were developed at METC to provide airblast atomization at low water flow rates, and pressure atomization at higher water flow rates. During testing, the nozzles operate at a fixed airblast air flow rate of $0.12 \mathrm{~kg} / \mathrm{s}(0.26 \mathrm{lbm} / \mathrm{s})$ air. The water flow rate is adjusted to establish an exhaust temperature above the dewpoint at the operating condition of interest. Thus, the quantity of quench water is not constant, but depends on the operating condition. As might be expected, the quantity of water affects the acoustic boundary at the exit of the Helmholtz neck. In some marginal cases, we observed that adding too much water ${ }^{1}$ could silence an oscillation, although the water did not appear to play a role in modifying resonant frequencies.

The Helmholtz resonator dimensions, V, S, and L, are used to determine the natural frequency of the resonator. The fuel nozzle inlet also plays a role, but we neglected the nozzle in design calculations. The inlet area is much smaller than the exit area, and the colder inlet gas is more dense than the exhaust, such that the inlet is a "hard" acoustic boundary relative to the exhaust. Janardan (1973) has measured the acoustic admittance of (rocket) nozzles/combustors having similar dimensions to the fuel nozzle and combustor studied here. Janardan showed that the nozzle acoustic admittance is almost zero, meaning the nozzle behaves acoustically like a solid wall. Notice this assumption depends on the relative size of the combustor and nozzle, and is not a general result. Neglecting the inlet area, the natural frequency $\left(f_{n}\right)$ of the Helmholtz resonator is given by

$$
f_{n}=\frac{c}{2 \pi} \sqrt{\frac{S}{V(L+\Delta L)}} \text {, }
$$

\footnotetext{
${ }^{1}$ Generally, as long as the exhaust temperature was above the dewpoint, the water did not have an obvious effect. Excess water, producing exhaust temperatures below the dewpoint, produced a significant damping effect.
} 
where the variables are identified:

$\mathrm{c}=$ the speed of sound in the burned combustion products,

$\mathrm{L}=$ the length of the combustion plug,

$\Delta \mathrm{L}=$ the "end" correction to the neck length (zero here, see below),

$\mathrm{S}=$ the cross section area of the neck opening,

$\mathrm{V}=$ the volume of the combustion zone.

For design purposes, the speed of sound can be calculated at the expected combustion temperature using properties of combustion gases. The end correction, $\Delta \mathrm{L}$, is an effective extension of the neck length due to the gas that oscillates downstream of the plug. The end correction must be accounted for in classic acoustic analysis of Helmholtz resonators where there is no mean flow moving through the resonator neck. In that situation, $\Delta \mathrm{L}$ has a value of 85 percent of the neck diameter, which for our case is a relatively small correction. However, large pressure oscillations (as expected here) and the presence of mean flow through the resonator tend to reduce the length of this correction factor; see the discussion by Laudien et al. (1995) and Janardan et al. (1976). In the METC combustor, the presence of the air assist spray quench disrupts the flow in the neck exhaust region, effectively removing the oscillating mass that contributes to the end correction. Thus, for design purposes, it is acceptable to neglect this correction so that we set $\Delta \mathrm{L}=0$.

We mention that equation (2) will predict the natural acoustic frequency of the Helmholtz resonator. This frequency will not precisely match the oscillating frequency when combustion driving is present. It is well-known that oscillating combustors will not operate at the natural frequency predicted by linear acoustics. The discrepancy depends on the phase relation between heat addition and the pressure waves, along with other factors; see Keller et al. (1989) for an example. Thus, equation (2) is a starting point for design; some adjustment after operation may be needed if precise frequencies are required.

The initial plug geometry and location were designed to produce a natural frequency of $300 \mathrm{~Hz}$. As explained previously, the combustion chamber diameter is set to match the engine application chamber diameter or annular height. The combustion chamber length was selected to provide approximately the same residence time as would exist in the engine configuration. Having established the diameter and length, the combustor volume is fixed, and equation (2) can be used to select the neck length $\mathrm{L}$ and cross-section area S. The tradeoff between $\mathrm{S}$ and $\mathrm{L}$ was based on fabrication considerations of the refractory plug. From earlier experience with castable refractory, we expected reasonable durability if the annular wall of the plug was (at least) $3.8 \mathrm{~cm}$ (1.5 in) thick. Based on these criteria, the following dimensions were used in the results reported here:
Combustion zone diameter:
$19.8 \mathrm{~cm}(7.80 \mathrm{in})$
Combustion zone length:
$19.8 \mathrm{~cm}$ (7.80 in)
Plug inside diameter:
$10.4 \mathrm{~cm}(4.10 \mathrm{in})$
Plug length:
$22.9 \mathrm{~cm}(9.00 \mathrm{in})$

We expected that we would need to adjust the location and dimensions of the refractory plug to activate various acoustic modes, and the initial plan was to design the rig so that the plug could be moved (with a screw-jack) while the rig was operating. As explained below, this adjustment was not necessary. 


\section{Combustor Instrumentation}

The combustor was equipped with dynamic pressure transducers connected to the inlet plenum, the exhaust plenum, and the combustion zone. The transducer attached to the combustion zone was mounted outside the pressure vessel, but connected via a 4.6-mm (0.18-in) ID stainless steel tube. The direct connection of a dynamic pressure transducer to a transmitting tube can record artificially large pressure signals because the wave travelling down the tube stagnates at the transducer face, and thus converts both the pressure and kinetic energy of the wave into a measured pressure signal. Also, spurious signals in the measured wave can originate from "organ pipe" excitation occurring at the $1 / 4$ wave frequency of the tube. One method to avoid these complications is described by Cutrone et al. (1985). The transducer is mounted on a tee connection, at a right angle to the transmitting tube with the remaining leg of the tee connected to a long length ( 8 meters [ 25 feet]) of tubing. The additional tubing acts as a termination damper, preventing reflected waves from distorting both the amplitude and waveform that is recorded. In a separate study, we considered the effect of transducer connection arrangements on dynamic pressure measurements, showing that measurement without the termination damper is generally not a problem, unless the measurement is made near the resonant point of the transducer tube (Richards et al. 1994). For simplicity, we did not use the termination damper in preliminary testing reported here, but its use is recommended where precise measurement of oscillating amplitude is needed.

In addition to the pressure transducer, we used one fiber optic probe to record the $\mathrm{OH}$ chemiluminescence signal from the combustor. The $\mathrm{OH}$ emission is proportional to the instantaneous value of the heat release (Keller and Saito 1987). Thus, the $\mathrm{OH}$ measurement is a representation of the term $\dot{Q}(\mathrm{t})$ in equation (1). The pressure term, $\mathrm{P}(\mathrm{t})$, comes from the pressure transducer. Together, these measurements can provide some insight into how the heat release and pressure are coupled together. One example of the use of the $\mathrm{OH}$ measure is provided later.

Figure 4 is a cut-away view of the fiber optic $\mathrm{OH}$ probe. The heart of the probe is a 1.6-mm (.0625-in) sapphire fiber, pressure-sealed using conventional compression fittings (with a graphite ferrule on the sapphire fiber). The viewing angle of the probe is determined by the geometry of the probe interior (or, at most, by the acceptance angle of the fiber that is 30 degrees included). Other tubing arrangements are easily envisioned, allowing installations on operating engines. As shown, the probe is fitted with a tee-connection to allow purge flow. This is not essential for natural gas operation, but would be necessary for testing on fuel oil combustion. The external side of the fiber was attached to a UV transmissive fiber optic cable, with the resulting signal detected by a standard photomultiplier tube (PMT). The PMT detector was fitted with an optical line filter, centered at the (optical) wavelength of interest for $\mathrm{OH}$ emission $(315 \mathrm{~nm})$. This probe was installed through a fitting in the pressure vessel and combustor liner, viewing across the combustor diameter at an axial station $2.54 \mathrm{~cm}$ (1.00 in) downstream of the fuel nozzle. The probe essentially replaced the sight glass optical access shown in Figure 3. 



M95001475W

Figure 3. Cut-Away and Cross-Section Views of the Test Combustor. (Note the scale on the upper figure.) 


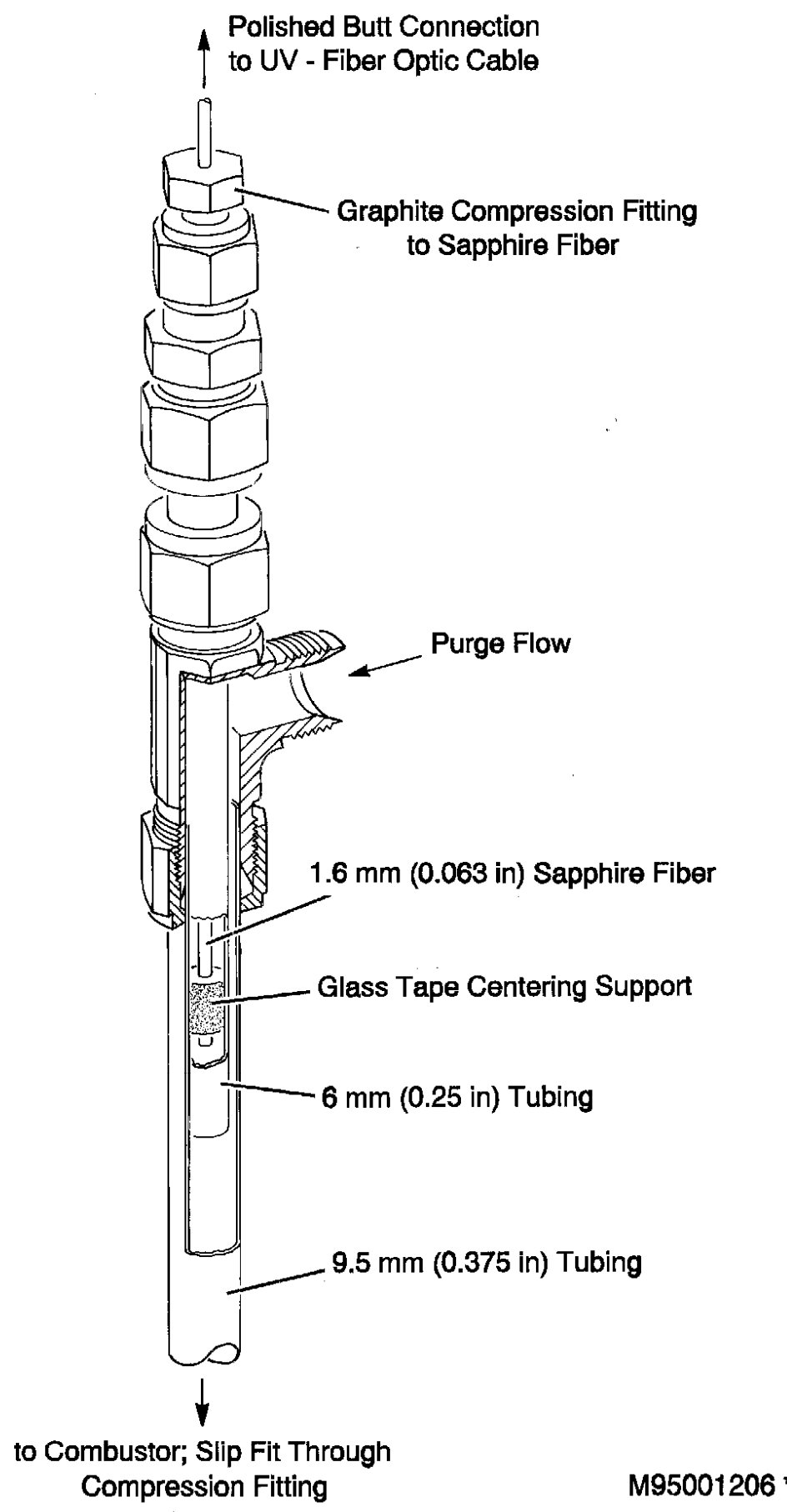

Figure 4. Fiber Optic Probe for Viewing $\mathrm{OH}$ Chemiluminescence. The $\mathrm{OH}$ signal is proportional to the combustion heat release. The probe used on the experiment described here used a slightly different tubing arrangement $(19 \mathrm{~mm}$ [0.75 in]) for mounting on the pressure vessel, and did not require air purge. 


\section{Preliminary Operating Experience}

We began testing the combustor by surveying various combinations of flow rate, operating pressure, and inlet air temperature. Table 1 lists four test cases (P1 through $\mathrm{P} 4)$ that were selected as representative of the behavior observed during the survey of operating conditions. The pressure and $\mathrm{OH}$ signals corresponding to these cases are shown in Figures 5, 6, 7, and 8. In Table 1, we describe the combustion air flow rate in terms of the reference velocity, which is the bulk velocity of air moving through the premixing nozzle. The reference velocity is calculated by dividing the nozzle air flow (mass per second) by the product of air density and nozzle cross-section area.

Table 1. Test Conditions Corresponding to Cases P1 Through P4

\begin{tabular}{|c|c|c|c|c|c|}
\hline Case & $\begin{array}{c}\text { Combustor } \\
\text { Pressure } \\
\text { (atm) }\end{array}$ & $\begin{array}{c}\text { Inlet } \\
\text { Temperature } \\
(\mathrm{K})\end{array}$ & $\begin{array}{c}\text { Reference } \\
\text { Velocity } \\
(\mathrm{m} / \mathrm{s})\end{array}$ & $\begin{array}{c}\text { Overall } \\
\text { Equivalence } \\
\text { Ratio }\end{array}$ & $\begin{array}{c}\text { Percent } \\
\text { Pilot }\end{array}$ \\
\hline $\mathrm{P} 1$ & 6.7 & 289 & 24.3 & 0.66 & 0.0 \\
\hline P 2 & 7.3 & 290 & 21.9 & 0.70 & 3.8 \\
\hline P3 & 4.8 & 396 & 38.6 & 0.79 & 5.8 \\
\hline P 4 & 6.1 & 538 & 74 & 0.55 & 3.1 \\
\hline
\end{tabular}

The cases P1 through P4 demonstrate that several different acoustic modes were easily excited, including the natural frequency of $300 \mathrm{~Hz}$. Starting with case P1, note that the pressure spectra and $\mathrm{OH}$ spectra are dominated by a $150-\mathrm{Hz}$ component, with a smaller component at $300 \mathrm{~Hz}$. This was typical of combustor operation with ambient inlet air temperatures. Comparison of the time history between pressure and $\mathrm{OH}$ reveals that the pressure signals include a smaller, but appreciable, perturbation leading the dominant pressure peak. The $\mathrm{OH}$ signal shows only an occasional perturbation prior to peak heat release. This observation suggests that the dominance of the $150-\mathrm{Hz}$ mode is the result of the combustion responding to every other natural acoustic cycle. Case P2 is a slight variation of this situation, where the $300-\mathrm{Hz}$ mode does dominate the pressure signal, but the heat release continues to oscillate at $1 / 2$ of the pressure cycle. Again, this type of behavior was very common during testing with ambient inlet air temperature.

We reasoned that the frequency of the heat release variation was limited by the low inlet air temperatures and low reference velocities. Low inlet air velocities produce a lengthy time lag between processes in the fuel nozzle and events occurring at the flame. Likewise, low inlet air temperatures will produce a lower flame speed, meaning the flame may stand off the nozzle. This will also lengthen the time required for feedback between the nozzle and flame. Thus, case P3 included air preheat and a higher reference velocity. The $\mathrm{OH}$ spectra and the pressure spectra are now both dominated by a 230 to $260 \mathrm{~Hz}$ signal. In contrast to cases P1 and P2, the time histories now show a correspondence between every pressure and 


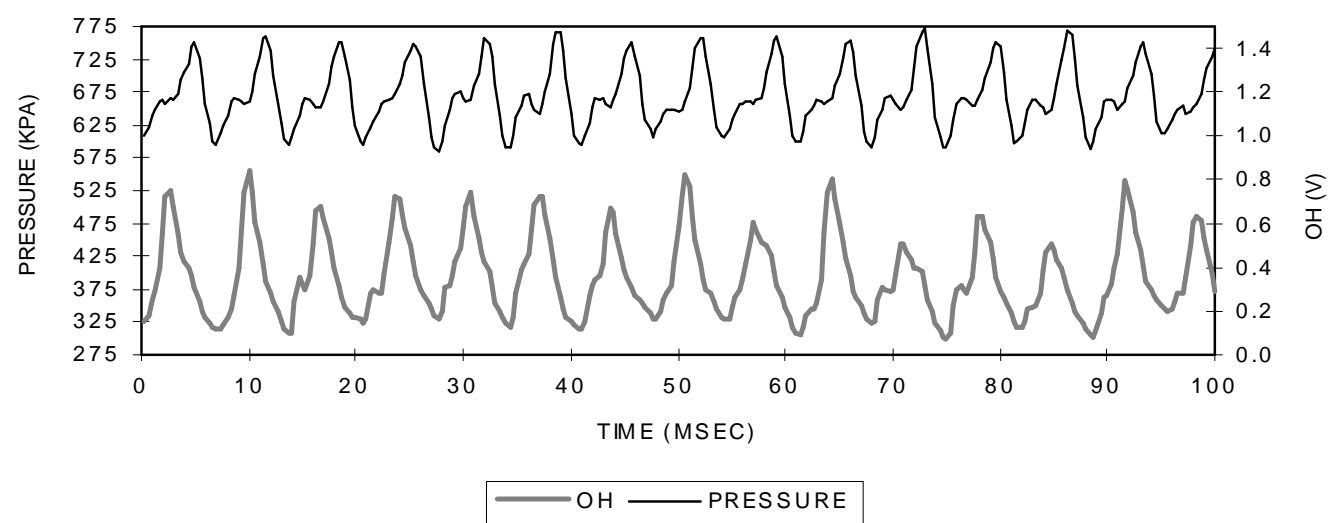

TCE 17

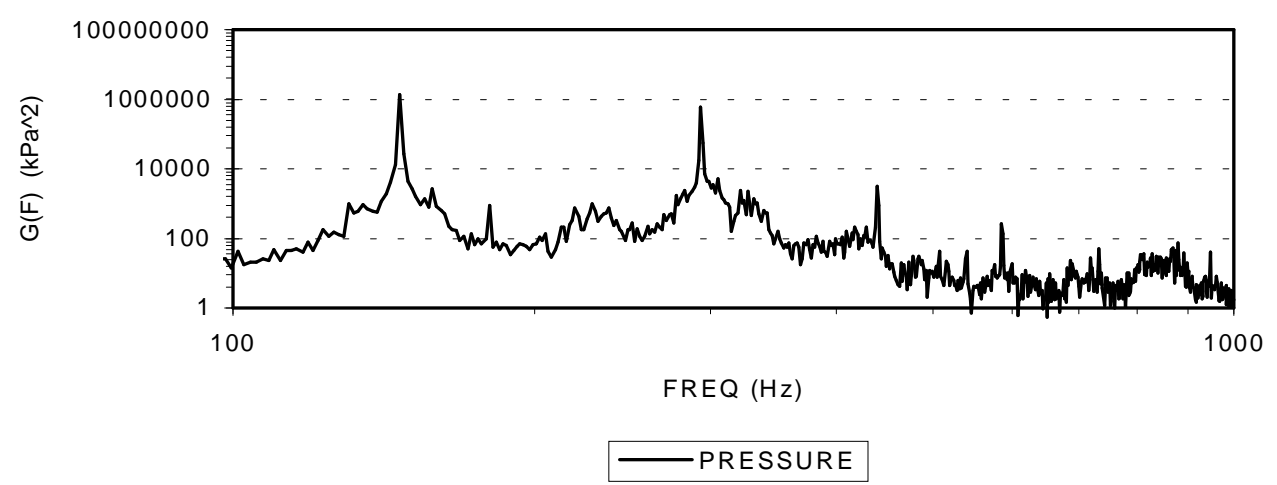

TCE 17

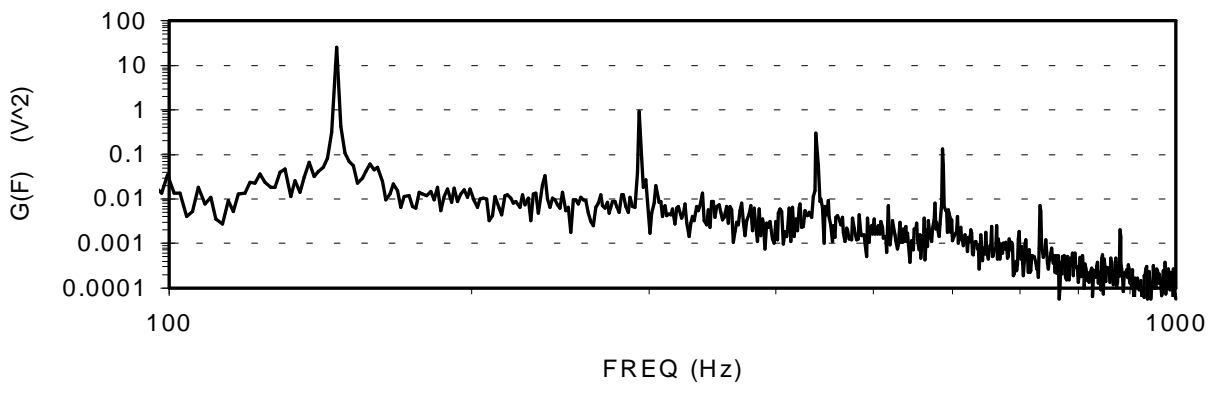

$\mathrm{OH}$

Figure 5. Pressure and OH Signals for Case P1 Listed in Table 1. Time history for the pressure and $\mathrm{OH}$ signals are shown in the top figure, with pressure and $\mathrm{OH}$ spectra shown at the center and bottom. 

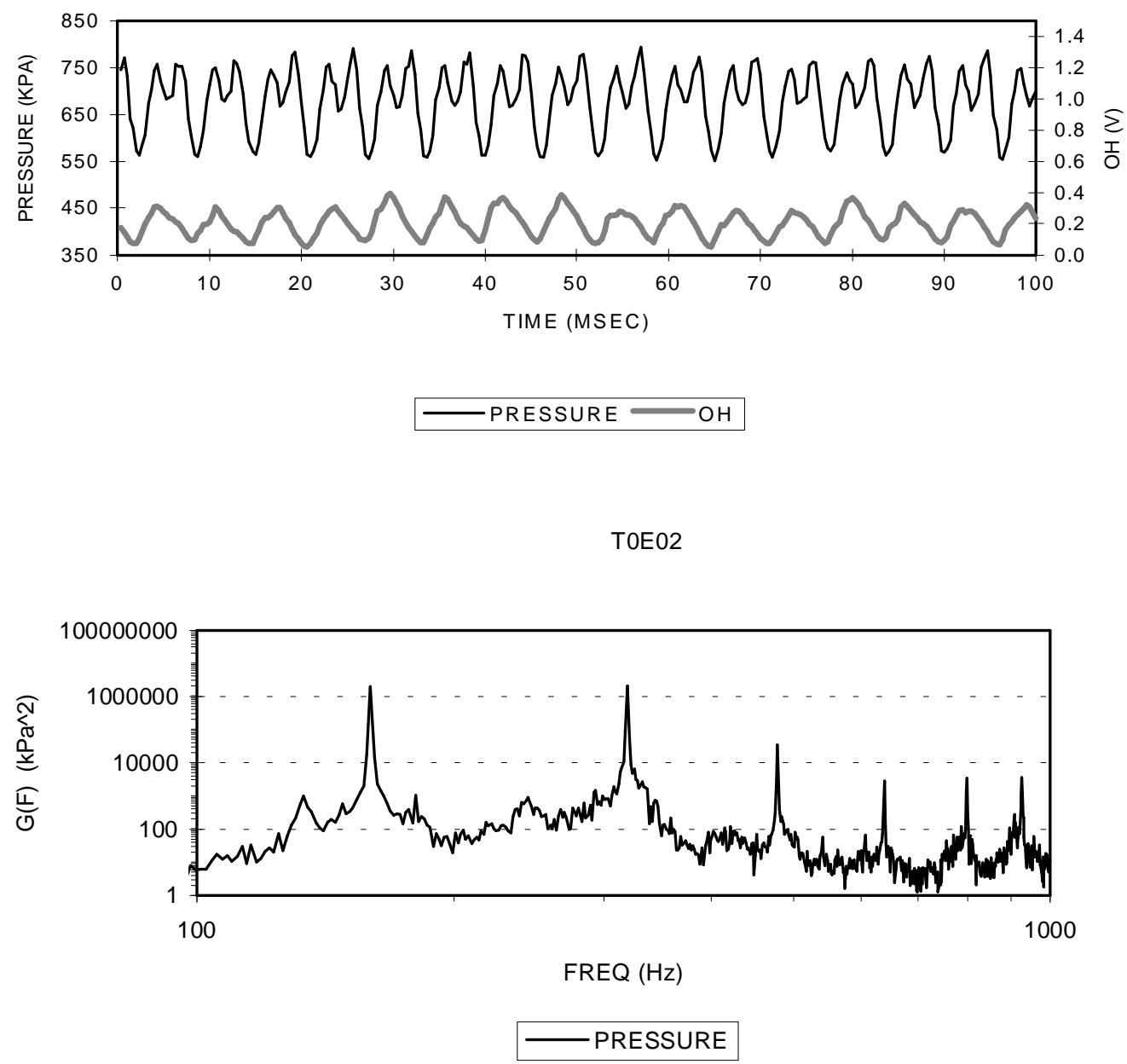

T0E02

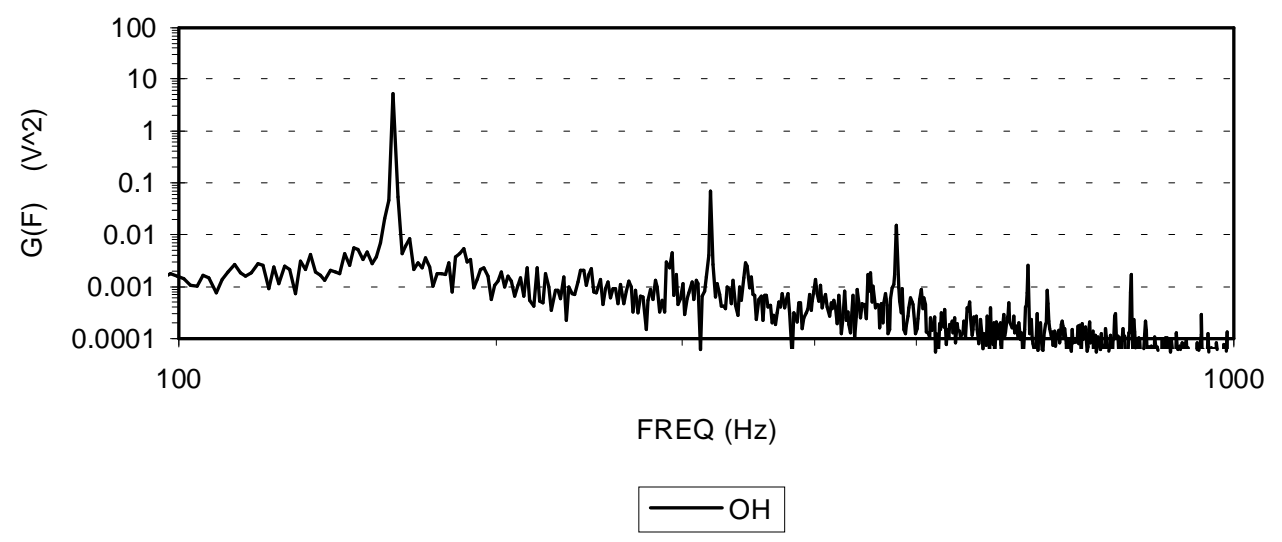

Figure 6. Pressure and OH Signals for Case P2 Listed in Table 1. 


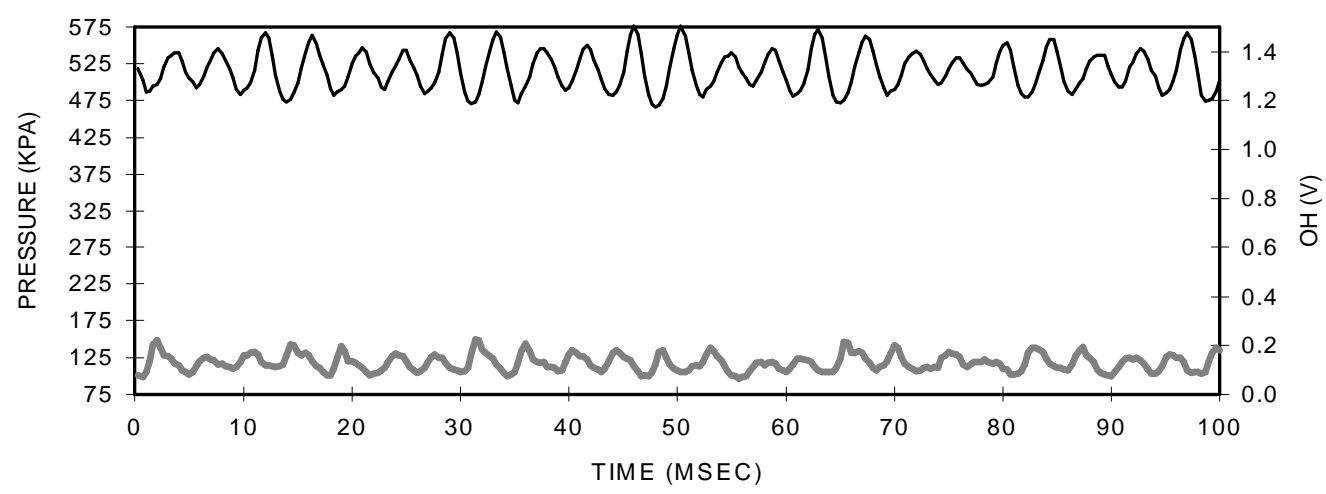

OH PRESSURE

TOE12

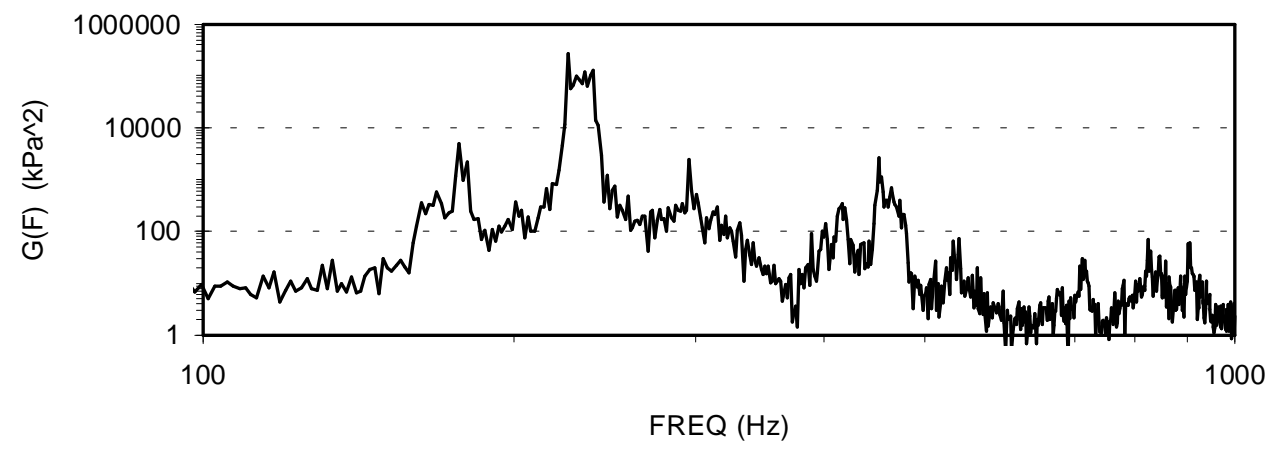

PRESSURE

TOE12

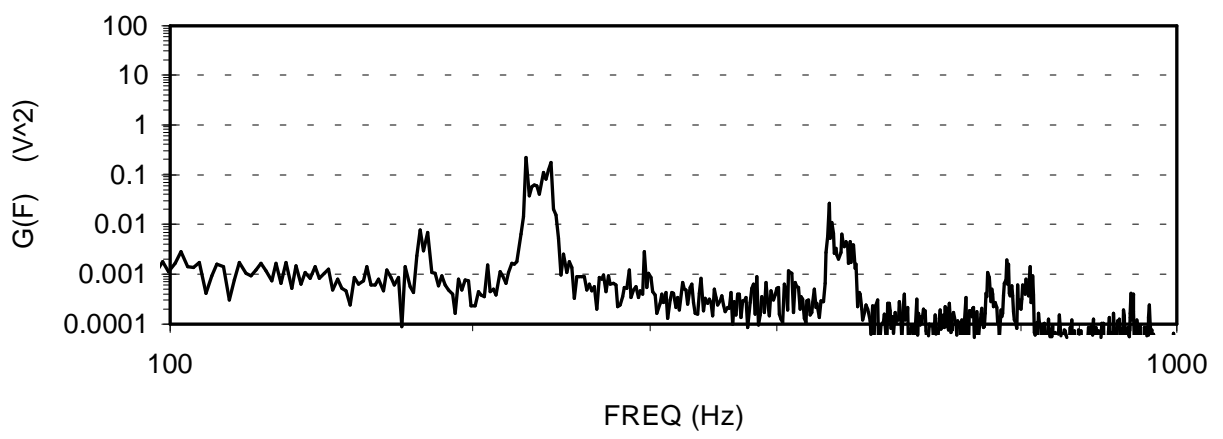

$-\mathrm{OH}$

Figure 7. Pressure and OH Signals for Case P3 Listed in Table 1. 


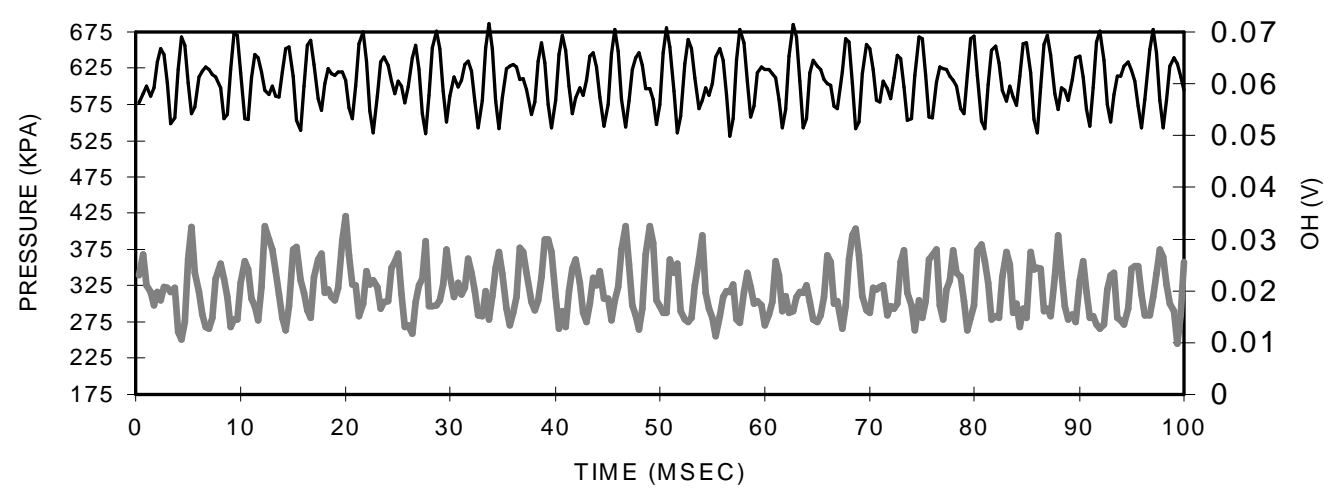

—

TXE15

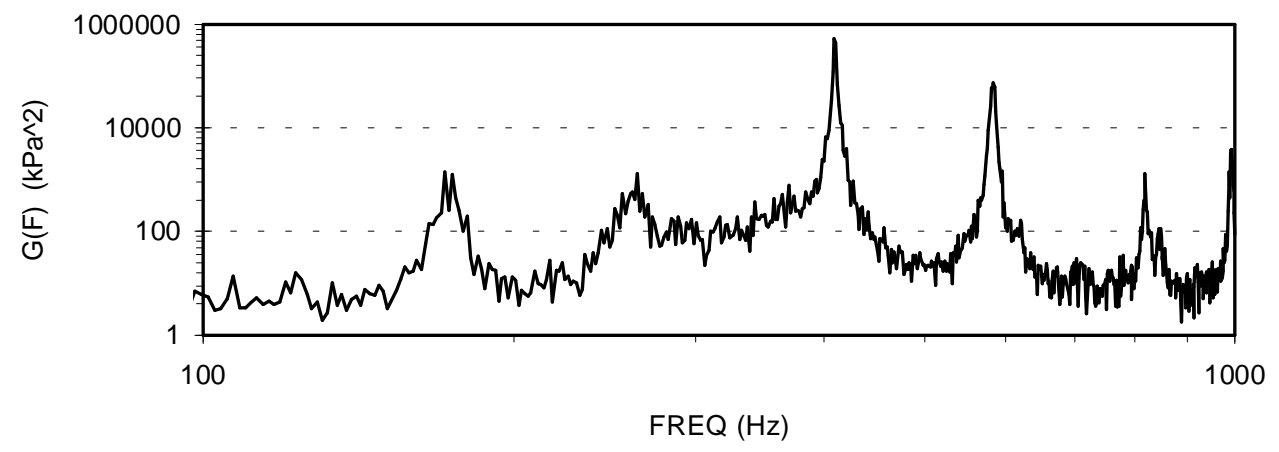

PRESSURE

TXE15
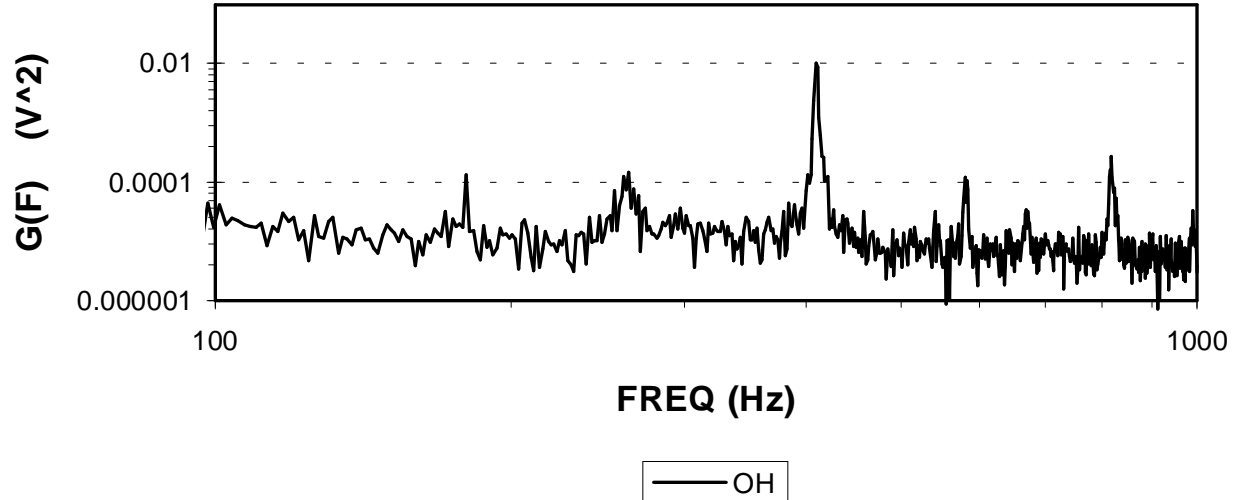

Figure 8. Pressure and OH Signals for Case P4 Listed in Table 1. 
$\mathrm{OH}$ peak, rather than every other peak. Many of the test cases run to date have included signals in the range of 230 to $260 \mathrm{~Hz}$, depending on the operating conditions. Note that this is slightly lower than the natural frequency of $300 \mathrm{~Hz}$. Part of this discrepancy may be due to the approximate nature of the natural frequency calculation (equation [2]), but also because oscillations will not necessarily occur at the natural acoustic frequency. As discussed previously, the phase between heat release and pressure will shift the operating frequency away from the natural frequency (Keller et al. 1989).

Finally, in case P4, we present results at a higher inlet air temperature and reference velocity. Here, a $410-\mathrm{Hz}$ mode is excited, appearing in both the pressure and $\mathrm{OH}$ spectra. This higher frequency oscillation was generally observed only at higher inlet air temperatures (greater than $530 \mathrm{~K}\left[495^{\circ} \mathrm{F}\right]$ ), and with larger reference velocities. Depending on operating conditions, we observed similar oscillations over a range of frequencies typically from 410 to $450 \mathrm{~Hz}$. Again, the oscillating frequency is not necessarily the natural acoustic frequency of $300 \mathrm{~Hz}$. It is interesting that these higher frequencies were activated without any changes in the geometry of the resonator. These higher frequencies are not explained by an increase in the speed of sound due to greater combustion temperatures associated with hotter inlet air. Notice the equivalence ratio is much lower in case P4 versus P3 (Table 1). We did not modify or move the resonator neck, as we thought would be necessary to activate various frequencies. At select conditions, we did identify some even higher frequencies (shown below).

The fuel nozzle used in these preliminary studies was also tested as a prototype on a commercial gas turbine engine. The same prototype nozzle was developed in a traditional single-nozzle test combustor, and appeared to be free of oscillations. Oscillations were observed in the engine application and the single-nozzle test device described in this paper. Below, the observed oscillating frequencies are compared between the engine and the singlenozzle test device:

\section{FREQUENCIES IN CYCLES PER SECOND (Hz)}

$\begin{array}{lcccc}\text { Engine: } & -- & 295 & 475 & -- \\ \text { Test Device: } & 150 & 230-260 & 410-450 & 2300-2500\end{array}$

The very high frequencies (2300 to $2500 \mathrm{~Hz}$ ) observed in the test device were the expected frequency for a transverse acoustic mode in the combustion zone volume. The low frequency, $150-\mathrm{Hz}$ mode was routinely observed in the test device when the inlet air temperature was ambient. This condition cannot be realized on an engine, which explains why no similar frequency was evident on engine tests. The middle frequency ranges were comparable between test stand and engine. On the engine, the choice of the $295-\mathrm{Hz}$ or $475-\mathrm{Hz}$ mode depended on the operating conditions, and the same was true in the test device at approximately the same conditions. The complex geometry of the engine combustor will allow multiple acoustic modes, but aside from the transverse mode, it is not obvious how the 
Helmholtz resonator produces both the central acoustic frequency ranges (230 to 260; 410 to 450). At this point, we propose that the bandwidth of the resonator is large enough that the combustion can generate an appreciable acoustic response over a range of frequencies, providing feedback between the heat release and acoustic pressure.

A complete investigation of oscillating combustion requires mapping the combustor performance over a wide range of operating conditions. Relevant parameters include the mass flow, the operating pressure, the inlet air temperature, the equivalence ratio, and, if applicable, the amount of pilot fuel. It may be possible to reduce the number of independent parameters by examining data in terms of the reference velocity. For many instability mechanisms, the reference velocity determines the time lag in the feedback between processes inside the fuel nozzle and at the flame front. For example, rich or lean pockets of fuel are transported down the nozzle at the reference velocity. Thus, the reference velocity may be more significant than the value of the mass flow, because the reference velocity accounts for the effect of changes in inlet density (i.e., temperature and pressure), which would otherwise be overlooked by comparing the mass flow alone. To demonstrate the significant role of the nozzle reference velocity, Figure 9 shows the measured RMS pressure as a function of reference velocity. The figure includes data at two different pressures $(6.4$ and $7.8 \mathrm{~atm})$ and with or without pilot fuel. When present, the pilot fuel was set at $0.54 \mathrm{~g} / \mathrm{s}(4.3 \mathrm{lbm} / \mathrm{h})$, which is less than 3.5 percent of the lean premix fuel flow at any of the conditions shown. The dominant frequency is shown near each of the operating points. The qualitative response of the combustor to the presence of pilot is the same at the two pressure levels, in spite of the appreciable difference in nozzle mass flow and operating pressure. In general, we found that the reference velocity and temperature were critical parameters, and the pressure was less critical. However, a slight change in pressure at a given mass flow would change the reference velocity. At conditions which were near the onset of oscillation, the pulsations could begin by a slight change in rig backpressure because of the change in the reference velocity. Because of this behavior, we found it was essential to closely replicate and maintain operating conditions, including the operating pressure. 


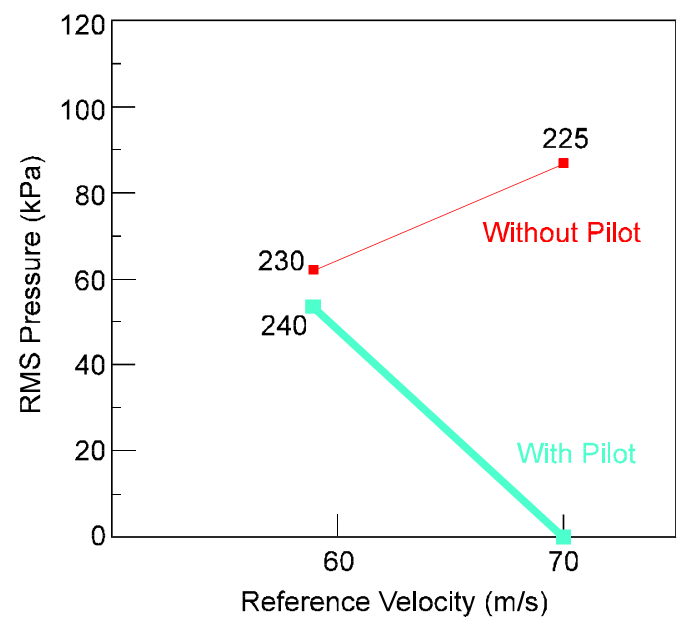

6.4 Atmospheres

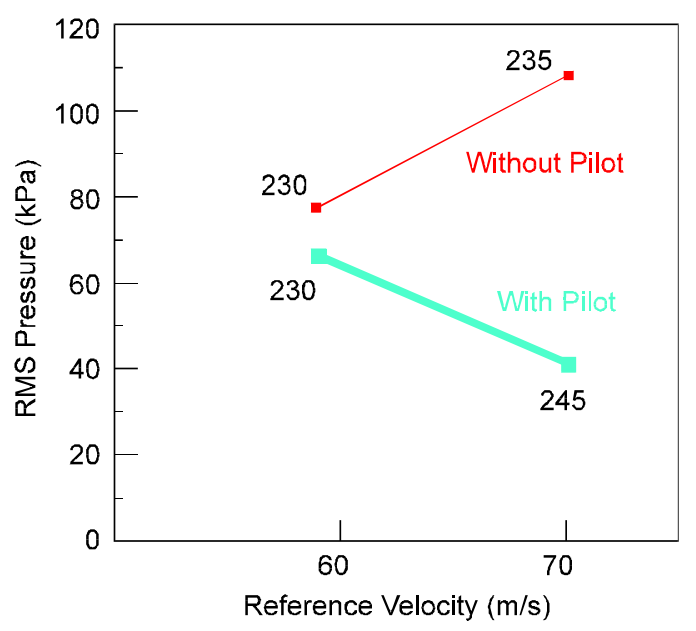

7.8 Atmospheres

Figure 9. Effect of Reference Velocity on the RMS Pressure at Different Pressures, and With or Without Pilot Fuel. Operating Condition: $533 \mathrm{~K}\left(550{ }^{\circ} \mathrm{F}\right)$ inlet air temperature, 0.56 equivalence ratio. 


\section{Summary and Conclusions}

This report discusses the development of a single-nozzle test device for studying lean, premixed combustion oscillations. The test device was used to study oscillations from a prototype fuel nozzle that produced oscillations during testing in a commercial engine. Similar (but not identical) oscillations were recorded in the single-nozzle test device.

The basic requirements of the test device design were that the flame geometry be maintained relative to engine testing, and the acoustic losses be minimized. This was achieved by using a Helmholtz resonator as the combustor geometry. Surprisingly, the combustor oscillated strongly at several frequencies, without modification of the resonator geometry. A brief survey of operating conditions suggests that it may be helpful to characterize oscillating behavior in terms of the reference velocity and inlet air temperature, with the rig backpressure playing a smaller role.

In conclusion, we emphasize that the preliminary results presented here do not guarantee that the single-nozzle test device will reproduce arbitrary oscillations that occur on a complete engine test. As already noted, nozzle/nozzle interactions may complicate the response that exists on an engine. Likewise, oscillations that are controlled by acoustic velocities transverse to the nozzle axis may not be reproduced in a test device that relies on a bulk, Helmholtz mode. Nevertheless, some oscillations can be reproduced, and the single-nozzle test device allows both active and passive control strategies to be tested in a relatively inexpensive environment. 


\section{References}

Alsup, C. T., C. M. Zeh, and S. Blazewicz, eds. 1995. Proceedings of the Advanced Turbine Systems Annual Program Review Meeting. 2 vols. DOE/METC-96/1023. NTIS/DE96000561 and NTIS/DE96000562. Springfield, Va.: National Technical Information Service.

Beer, J. M. 1995. Clean Combustion in Gas Turbines: Challenges and Technical Responses - A Review. Journal of Institute of Energy 68: 2-10.

Candel, S. M. 1992. Combustion Instabilities Coupled by Pressure Waves and Their Active Control. In the Twenty-Fourth (International) Symposium on Combustion 1277-1296.

Cutrone, M. B., J. Hook, W. B. Hibbins, and J. D. Corbett. 1985. High Reliability Gas Turbine Combustor Project. EPRI AP-3885. Project 1801-1, Final Report. Available from the Electric Power Research Institute, Palo Alto, Ca.

Halow, J. S., D. J. Maloney, and G. A. Richards. 1994. METC Combustion Research Facility. In Proceedings of the Advanced Turbine Systems Annual Program Review Meeting. DOE/OR-2025.

Harrje, D. T., and F. H. Reardon. 1972. Liquid Propellant Rocket Combustion Instability. NASA SP-194.

Janardan, B. A. 1973. Damping of Axial Instabilities by Solid Propellant Rocket Exhaust Nozzles. Ph.D. Thesis, Georgia Institute of Technology.

Janardan, B. A., B. R. Daniel, and B. T. Zinn. 1976. Measurements of Acoustic Responses of Gaseous Propellant Injectors. Journal of Sound and Vibration 47(4): 559-569.

Keller, J. O., and K. Saito. 1987. Measurement of the Combusting Flow in a Pulse Combustor. Combustion Science and Technology 53: 137-163.

Keller, J. O., T. T. Bramlette, J. E. Dec, and C. K. Westbrook. 1989. Pulse Combustion: The Importance of Characteristic Times. Combustion and Flame 73: 33-44.

Laudien, E., R. Pongratz, P. Pierro, and D. Preclik. 1995. Experimental Procedures Aiding the Design of Acoustic Cavities. In Liquid Rocket Combustion Instability 377-399. Published by the American Institute of Aeronautics and Astronautics. Cambridge, Ma.

Lefebvre, A. H. 1995. The Role of Fuel Preparation in Low Emission Combustion. ASME Journal of Engineering For Gas Turbines and Power 117: 617-654.

McManus, K. R., T. Poinsot, and S. M. Candel. 1993. A Review of Active Control of Combustion Instabilities. Progress in Energy and Combustion Science 19: 1-29. 
Putnam, A. A. 1971. Combustion Driven Oscillations in Industry. New York: American Elsevier Publishers.

Richards, G. A., R. S. Gemmen, and L. Narayanswami. 1994. Aerovalve Pulse Combustion. Technical Note. DOE/METC-94/1009. NTIS/DE94012262. Springfield, Va.: National Technical Information Service.

Yang, V., and W. Anderson \{eds.\}. 1995. Liquid Rocket Combustion Instability. Published by the American Institute of Aeronautics and Astronautics. Cambridge, Ma. 